\title{
Evaluation and mitigation analysis of carbon footprint for an airline operator: Case of Nepal Airlines Corporation
}

\author{
Sandeep Tuladhar ${ }^{a, *}$, Tri Ratna Bajracharya ${ }^{a, b}$ and Shree Raj Shakya ${ }^{a, b}$ \\ ${ }^{a}$ Department of Mechanical Engineering, Pulchwok Campus, Institute of Engineering, Tribhuvan University, Lalitpur, Nepal \\ ${ }^{b}$ Center for Energy Studies, Institute of Engineering, Tribhuwan University, Lalitpur, Nepal
}

\section{ARTICLE INFO}

\section{Article history:}

Received 31 Dec 2020

Received in revised form

26 Jan 2021

Accepted 06 Feb 2021

Keywords:

Carbon footprint

Nepal Airlines

Mitigation

Distance

Fuel

\begin{abstract}
This paper deals with evaluation and analysis of carbon footprint of an airline operator, Nepal Airlines Corporation (NAC) by using its actual flight and maintenance data from 2016 to 2019. NAC is a multi-fleet operator, of both turboprop and turbofan aircrafts. Carbon footprint in terms of Carbon Dioxide $\left(\mathrm{CO}_{2}\right)$ emission has been calculated for NAC's airline operations per individual aircraft, fleet-type and operating sector (i.e., international and domestic), and total ground handling operations. In each of the study years, contribution to NAC's total $\mathrm{CO}_{2}$ production from its domestic fleet was found out to be very small (below $6 \%$ of yearly total), even though its fleet number outnumbered that of international fleet. This indicates better optimization opportunities for international-sector (turbofan) aircrafts than domestic-sector (turboprop) aircrafts. Reductions in fuel on-board as per prescribed levels, better airport slot management and selection of long-haul flight destinations have been identified as potential mitigation strategies for $\mathrm{CO}_{2}$ emission from international sector. Smaller aircrafts operating in domestic sectors are more prone to variations in occupancy rate and as such, NAC could focus on optimizing its commercial strategy to improve its $\mathrm{CO}_{2} /$ passenger rate in domestic sector
\end{abstract}

CJIEE Thapathali Campus, IOE, TU. All rights reserved

\section{Abbreviations and acronyms}

A320 : Airbus A320-200 Ceo aircraft

A330 : Airbus A330-200 aircraft

AFL : Aircraft Flight Log

APU : Auxiliary Power Unit

B757 : Boeing 757-200M aircraft

$\mathrm{CO}_{2}$ : Carbon Dioxide gas

DHC-6 : De Havilland Canada-6/300 aircraft

EASA : European Aviation Safety Agency

FAA : Federal Aviation Administration

FOB : Fuel on Board

GHG : Green House Gas

ICAO : International Civil Aviation Organization

\footnotetext{
*Corresponding author:

@ tuladhars-sandeep@hotmail.com (S. Tuladhar)
}

KTM : Tribhuwan International Airport, Kathmandu

MA60 : Modern Ark 60 aircraft

NAC : Nepal Airlines Corporation

OEM : Original Equipment Manufacturer

OEW : Operational Empty Weight

PAX : Passengers

RF : Radiative Forcing

STOL : Short Take-Off and Landing

AFL : Aricraft Flight Log

TOW : Take-off Weight

PIC : Pilot in Command

Y12-E : Harbin Y12-E aircraft

TFBPF : Total fuel burn per flight

PTFF : Pax-to-freight factor

NOYS : Number of y-seats 
Evaluation and mitigation analysis of carbon footprint for an airline operator: Case of Nepal Airlines Corporation

$\begin{array}{ll}\text { PLF } & \text { : Pax load factor } \\ \text { OEW } & \text { : Operational empty weight }\end{array}$

\section{Introduction}

Carbon footprint is defined as the total greenhouse gas (GHG), primarily carbon dioxide $\left(\mathrm{CO}_{2}\right)$ caused by an individual, event, organization or product expressed as carbon dioxide equivalent $\left(\mathrm{CO}_{2} \mathrm{e}\right)$ [1]. There are two types of carbon emissions: direct and indirect [2]. Within the direct emission type, scope 1 emissions are of interest in aviation sector because it measures direct emissions from the source, like burning of fuels. Scope 2 emissions, which are from use of utilities like electricity and heat, and Scope 3 emissions which are from upstream and downstream of the end use are secondary emissions.

Radiative Forcing (RF) is a term used for determining the heating or cooling effect of GHGs (which include carbon dioxide, nitrogen oxides, hydrocarbons, water vapor and aerosols). According to ICAO, the net RF by all GHGs in the environment due to aircrafts is heating effect. It is to be noted that a large representative fraction of RFs from all GHGs is from $\mathrm{CO}_{2}$ alone [3]. The RF of most GHGs other than $\mathrm{CO}_{2}$ are variable over time. Moreover, uncertainties concerning the impact of some of the GHGs like $\mathrm{NO}_{x}$ (Nitrogen Oxides) emitted at high altitudes, contrails and contrail cirrus still exists [4]. Even though the full impact of aviation always results in larger climatic effects than considering $\mathrm{CO}_{2}$ alone, the emission ratio: $\left(\mathrm{CO}_{2}+\right.$ non- $\left.\mathrm{CO}_{2}\right)$ per $\mathrm{CO}_{2}$ is not a constant but rather depends on the individual flight and on the flight length [4]. Such uncertainty in quantification of RF from GHGs other than $\mathrm{CO}_{2}$ is also voiced in IPCC special report [5]. Thus, it is logical to say that within an airline company, only the carbon emission would suffice as the value to be compared to analyze the underlining cause and effect of carbon emission summing up to carbon footprint as a whole. Thus, this paper deals with the carbon footprint considering $\mathrm{CO}_{2}$ emission only.

Aviation sector accounts to $2 \%$ of the total human induced $\mathrm{CO}_{2}$ emissions [6] and around $12-18 \%$ of emissions of all types of transportation sectors. The active global commercial fleet as of 2017 stands at above 25,000 aircrafts. The next 10 years will see $3.4 \%$ net annual growth, increasing the number to around 35,500 [7]. This projection though is hampered by the COVID19 situation, will have a net growth in the coming years.

This clearly signifies the increase in fuel consumption by airlines and thus, more $\mathrm{CO}_{2}$ emission in future. Most of today's operational aircrafts are either of newest technology or old ones which are incorporated with at least minimal modifications to be at par with the existing regulatory requirements. For instance, from 2013, all aircraft engines produced had to comply with ICAO/CAEP6 NOx limits but all aircraft engines in production since then are already performing better than this regulatory limit [8].

While there are opportunities to reduce $\mathrm{CO}_{2}$ emissions from the OEM and aviation authorities' level through design changes or modification incorporation, airline operator themselves can contribute to reducing $\mathrm{CO}_{2}$ emission via increase in operational efficiency and mitigation tactics which can help to reduce the cost in implementing emission trading scheme [4].

Both FAA and IATA have set targets of carbon neutrality till 2020, while FAA has stated for net reductions by 2050 and IATA has set net reductions in 2050 by 50\% (taking 2005 as base year). Also, there are requirements established by Civil Aviation Authority of Nepal (CAAN) applicable to an aeroplane operator that produces annual $\mathrm{CO}_{2}$ emissions greater than 10,000 tons from the use of an aeroplane(s) with a Maximum Takeoff mass greater than $5,700 \mathrm{~kg}$ conducting international flights on or after 1st January, 2019 [9].

Carbon accounting is the process by which organizations quantify their GHG emissions, so that they may understand their climate impact and set goals to limit their emissions [10]. Carbon accounting has been done for NAC by compilation of comprehensive flight and maintenance data of aircrafts operated by NAC over the period of 2016-2019.

There are many ways by which an airline operator can mitigate and offset is carbon emission. Induction of new fleets with most modern aircraft can reduce carbon emission [11, 12]. Carbon offsetting through purchase of carbon credits and supporting projects dealing in sustainable development goals has enabled Yeti Airlines to be carbon neutral as of 2018 [13]. Varying the controllable causative factors (like: FOB, routes and flight time) of $\mathrm{CO}_{2}$ emission over a future tenure provides insight into operational efficiencies NAC can add to reduce its $\mathrm{CO}_{2}$ emissions.

\section{Methodology}

Raw data for flights operated by NAC from 2016-2019 have been obtained from Aircraft Flight Log (AFL), which is proprietary to Continuing Airworthiness Management part of NAC. The raw data include flight information like: city pair, flight (air) time, fuel on board, fuel burnt, take-off weight, logged engine hours and 
APU hours (if installed). Then, calculation of $\mathrm{CO}_{2}$ emission from fuel burn for each flight was calculated using ICAO's methodology.

\section{1. $\mathrm{CO}_{2}$ Calculation}

The ICAO calculator has been explicitly used by many researches like by Yang et.al. 2020 [14] and Debbage et.al. 2019 [15] including CAAN's CAAN Carbon Offsetting and Reduction Scheme for International Aviation (CORSIA) [9]. The ICAO (2017) methodology calculates carbon emissions for specific city-pair markets based on the great circle distance between any two given airports that offer scheduled flights. While the great circle paths do not necessarily correspond to flown flight paths, a correction factor is applied by the ICAO to account for the emissions associated with additional flight distance due to air traffic and weather conditions. Using published flight itineraries, the ICAO calculator determines the aircraft types that service the route and then each aircraft is mapped to one of 312 equivalent aircraft types to calculate fuel consumption [16].

Since actual data are available for the airline company, NAC, use of this ICAO methodology is free from deviations pertaining to assumptions of fuel burn generalized for the aircraft type and region of operation.

As per the methodology, $\mathrm{CO}_{2}$ (in tons) equals to 3.16 times the fuel burn (in tons). $\mathrm{CO}_{2} /$ pax is measured using $1,2 \& 3$.

$\mathrm{CO}_{2}$ per pax $=3.16 \times \frac{\mathrm{TFBPF} \times \mathrm{PTFF}}{\mathrm{NOYS} \times \mathrm{PLF}}$

Where,

$$
\begin{aligned}
\text { PTFF } & =\frac{\text { Pax weight }}{\text { Pax weight }+ \text { Cargo weight }} \\
\text { NOYS } & =\frac{\text { Actual pax }}{\text { y-seats }}
\end{aligned}
$$

ICAO uses a standard $80 \mathrm{~kg}$ per passenger regardless of passenger gender or ratio while FAA uses a $60: 40$ male to female ratio at $83 \mathrm{~kg}$ and $73 \mathrm{~kg}$ respectively. EASA established weights of $95 \mathrm{~kg}$ and $75 \mathrm{~kg}$ for male and female respectively. An additional estimation of passenger baggage is added to the overall payload, assuming that each item of luggage is $25 \mathrm{~kg}$ and that $70 \%$ of the passengers take one bag and 30\% take two bags. Also, study show that in Indian region (which is closest example for Nepal) the standard weight of passenger is $75 \mathrm{~kg}$ [17]. This provides us a standard weight with hand luggage standing at $100 \mathrm{~kg}$. Because the cargo weight is not documented in AFL, for each flight, it can be calculated from 4
Freight $=$ Take-off Weight (Tons) - FOB

$$
\text { (Tons) } \times 0.8 \times 1000-\mathrm{OEW}
$$

An average specific gravity of 0.8 is assumed for the aviation fuel used [9]. Because the actual number of passengers per flight is used, there is no requirement of pax-load factor. The operational empty weight (OEW) and passenger capacity for aircrafts of NAC have been obtained from OEM's manuals as in Table 1:

Table 1: OEW and Pax capacity for NAC's aircraft

\begin{tabular}{lll}
\hline Aircraft & OEW & Pax capacity \\
\hline B757 & $43,670 \mathrm{~kg}$ & 190 \\
A330 & $124,870 \mathrm{~kg}$ & 274 \\
A320 & $58,800 \mathrm{~kg}$ & 158 \\
DHC-6/300 & $3,674 \mathrm{~kg}$ & 19 \\
MA60 & $13,720 \mathrm{~kg}$ & 56 \\
Y12-E & $3,800 \mathrm{~kg}$ & 17 \\
\hline
\end{tabular}

Data for only revenue flights (which constitute $90 \%+$ of the total flights) taken place between pre-scheduled operating city pairs have been considered for this research. Remaining data of flights for charter, test flight or ferry flights have not been considered for data analysis.

\subsection{Evaluation of Total and Specific $\mathrm{CO}_{2}$ emission}

By use of ICAO's methodology, NAC's AFL and OEM's data, $\mathrm{CO}_{2}$ for each flight was calculated. Total carbon emission was evaluated for domestic and international sectors on yearly basis. Yearly $\mathrm{CO}_{2}$ emission per engine hours was evaluated to study the effect of engine utilization on $\mathrm{CO}_{2}$ emission over passage of time. The average fuel burn per kilometer is a good measure of a fleet's ecological impact [18] and thus $\mathrm{CO}_{2} / \mathrm{km}$ and the corresponding route distance has been evaluated to measure particular fleets' efficiency in terms of $\mathrm{CO}_{2}$ generated per km flown. $\mathrm{CO}_{2}$ emission per passenger and kilometer travel has been used as a common parameter of comparison between different aircrafts of different engine types, range and region of operation. As a measure of possible $\mathrm{CO}_{2}$ emission mitigation, sector fuel for each city pair has been predicted form historical data, aeronautical theories and fuel policy of NAC.

\subsection{Additional Data Collection for Specific $\mathrm{CO}_{2}$ emission}

The route distance, which is the actual standard distance which is constant for a particular set of cities developed specifically for NAC. While the actual distance flown does deviate from this value, this approximation of actual distance is more accurate than the great circle distance used by ICAO calculator. Flight distance 
for different city pairs of as per NAC's flight routes are given in Appendix A. The aircraft fleet for NAC operational over the years: $2016-2019$ is shown in Table 2.

\subsection{Correlation and regression analysis}

Analysis of sectoral $\mathrm{CO}_{2}$ emission showed the percentage of carbon emission from domestic sector to be very small in comparison to international sector. By use of Excel tools for correlation and regression analysis, the major contributing factors of $\mathrm{CO}_{2}$ emissions have been established for international-sector aircrafts. The paper deals more in-depth with the aircrafts operated in international sector i.e., the turbofan aircrafts.

By this analysis, possible mitigation measures have been put forward. The $\mathrm{CO}_{2}$ emission by year has been initially projected to the year, 2021 considering effect of flight suspensions, international charter flights and flight resumptions in 2020 due to COVID-19 outbreak and decommissioning of its Chinese aircrafts' fleet (i.e., MA60 and Y12E aircrafts). Six months of the year, 2020 were affected due to Civil Authority of Nepal on commercial flights due to COVID-19 situation. Even though chartered flights were carried out via international aircrafts during the lockdown period, those were sparingly distributed over time and did not represent the scheduled commercial flights of NAC. After the resumption of flights, commercial flights saw operation only up to $20-30 \%$ of the capacity as was in 2019 . This value assumed to grow, to $50 \%$ by end of first half of 2021 and gain full operation by $3^{r d}$ quarter of 2021 .

Crystal Ball predictor has been used to predict the $\mathrm{CO}_{2}$ emissions with the existing fleet of NAC with two different scenarios: one without the impact of COVID-19 and another without its impact, as though flights were presumed to grow without restrictions. The $\mathrm{CO}_{2}$ emissions were first projected to 2021 using inbuilt Forecast tool and then the data from 2016 - 2021 were used to carry out prediction till 2030. Iterations of 5000 were used to create the predictive model for the two scenarios.

\section{Results}

\section{1. $\mathrm{CO}_{2}$ emission of NAC flight operations}

Using theoretical background and data processing, the total $\mathrm{CO}_{2}$ emission of NAC segregated into aircraft fleets and domestic/international sector has been presented.

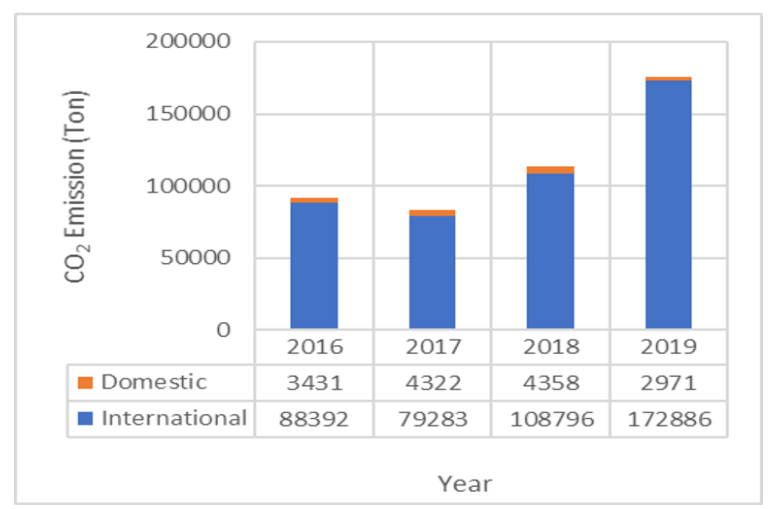

Figure 1: $\mathrm{CO}_{2}$ emission of NAC from Domestic and International flight operations (2016 - 2019)

Figure 1 clearly depicts that the $\mathrm{CO}_{2}$ emission contribution from domestic flights operations is very low in comparison to the yearly carbon emission. The yearly

Table 2: Aircraft operation data for 2016-2019

\begin{tabular}{|c|c|c|c|c|}
\hline $\begin{array}{l}\text { Aircraft } \\
\text { type }\end{array}$ & Call Sign & $\begin{array}{l}\text { Operational } \\
\text { Years from } \\
2016-2019\end{array}$ & $\begin{array}{c}\text { Operating } \\
\text { Sector / } \\
\text { Aircraft Type }\end{array}$ & $\begin{array}{c}\text { Non- } \\
\text { operational } \\
\text { after }\end{array}$ \\
\hline DHC-6/300 & 9N-ABT & 2016-2019 & \multirow{8}{*}{$\begin{array}{l}\text { Domestic } \\
/ \\
\text { Turboprop }\end{array}$} & - \\
\hline Twin otter & 9N-ABU & 2016-2019 & & - \\
\hline Modern Ark & 9N-AKQ & 2016-2018 & & 2018 \\
\hline 60 & 9N-AKR & 2017-2019 & & 2019 \\
\hline & 9N-AKS & 2016-2018 & & 2018 \\
\hline Harbin & 9N-AKT & 2017-2019 & & 2019 \\
\hline \multirow[t]{2}{*}{ T12-E } & 9N-AKU & 2018-2019 & & 2019 \\
\hline & 9N-AKV & 2018-2019 & & 2019 \\
\hline Boeing & 9N-ACA & 2016 & \multirow{6}{*}{$\begin{array}{c}\text { International / } \\
\text { Turbofan }\end{array}$} & 2016 \\
\hline $757-200$ & 9N-ACB & 2016-2018 & & 2018 \\
\hline Airbus & 9N-AKW & 2016-2019 & & - \\
\hline A320-200 & 9N-AKX & 2016-2019 & & - \\
\hline Airbus & 9N-ALY & 2018-2019 & & - \\
\hline A330-200 & 9N-ALZ & 2018-2019 & & - \\
\hline
\end{tabular}


$\mathrm{CO}_{2}$ production from domestic operations are (as $\%$ of total production): $3.7 \%, 5.2 \%, 3.9 \%$ and $1.7 \%$ for 2016 , 2017, 2018 and 2019, respectively. The carbon emission by domestic sector increased in year 2017 because new Y12-E aircrafts were introduced into the fleet and other domestic fleets were also operating in full capacity. During the same time i.e., 2017, one of the Boeing 757 aircraft was removed from NAC's fleet which explains the increase in contribution in carbon emission by domestic sector. In the year 2018, the remaining Boeing 757 aircraft was also decommissioned while two new Airbus A330 aircrafts were added to the fleet. During the same year, one MA60 and several Y12-E aircraft suffered AOG (Aircraft on Ground) situations which explains to the drop in contribution of emissions from domestic sector flights. Lastly, in 2019, many of MA60 and Y12-E aircrafts have experienced irregular operations while the DHC-6/300 seemed to be the sole aircraft fleet operating regularly in the domestic sector. Also, the newly inducted A330 aircrafts were being operated in full fledge by 2019 which resulted in sudden drop of carbon emission contribution by domestic sector.

Figure. 2 explains the phenomenon of $\mathrm{CO}_{2}$ production share of each aircraft over the years.

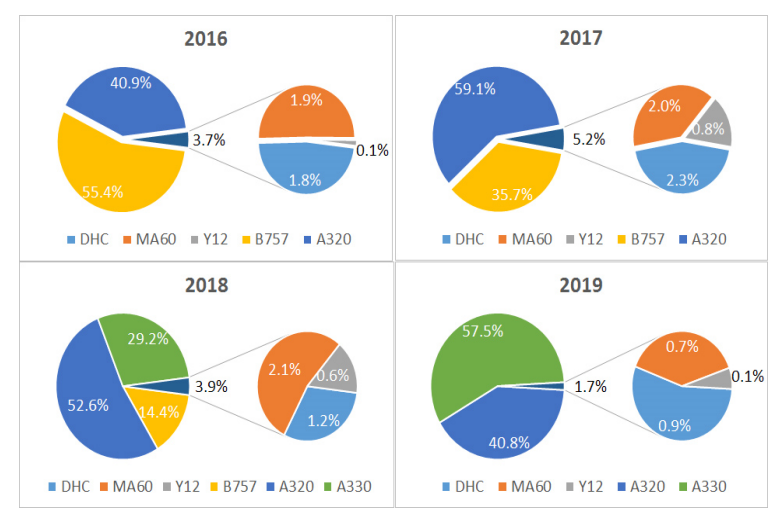

Figure 2: $\mathrm{CO}_{2}$ emission share of NAC aircrafts (20162019)

Since the $\mathrm{CO}_{2}$ emission generated by domestic sector aircrafts is much lesser than international sector aircrafts, detailed analysis of causative factors have been done for only the international sector aircrafts (i.e., turbofan aircrafts).

\subsection{Driving factors of $\mathrm{CO}_{2}$ emission}

Scatter plots between different parameters were obtained from the available and calculated data. The correlation parameter, $\mathrm{R}^{2}$ provides us how much of a resultant parameter is affected by a causative parameter. Here, individual, one on one correlation analysis has been done to determine how much effect a causative factor (like: flight time, route distance, take-off weight, fuel on board and number of passengers) has on the resultant output (in this case, $\mathrm{CO}_{2}$, and its derivatives being subject of interest).

Similarly, trend line corresponding to the scatter plots were made and its equations were generated from Excel tools. The gradient value of the simple straight line thus lets us quantify sensitivity of output parameter with respect to changes in the input parameter.

\subsection{Variation in $\mathrm{CO}_{2}$}

Table 3 summarizes the $\mathrm{R}^{2}$ value for correlation between the given parameters and respective intercept values for each turbofan aircraft, which are sorted in order of their Maximum Take-Off Weight (MTOW). The results seen in the table infer that there is strong statistical significance between $\mathrm{CO}_{2}$ emission and the flight time $\left(\mathrm{R}^{2}=\right.$ 0.970 to 0.970$)$ and route distance $\left(R^{2}=0.897\right.$ to 0.941$)$. Thus, one hour of flight time corresponds to $7.79,12.11$ and 15.64 tons of $\mathrm{CO}_{2}$ emission for $\mathrm{A} 330, \mathrm{~B} 757$ and A320 aircraft. Even though the $\mathrm{CO}_{2}$ emission is directly proportional to the route distance, the $\mathrm{CO}_{2} / \mathrm{km}$ value (as will be discussed later) decreases with respect to increase in route distance, and this decreasing rate also increases with the aircraft MTOW.

Fuel on board the aircraft is a parameter of particular interest, because there is good statistical significance of FOB on $\mathrm{CO}_{2}$ emission. One ton of FOB in average corresponds to 1.78 to 2.63 tons of $\mathrm{CO}_{2}$ emission produced. Here, it is to be noted that smaller aircraft (A320) has much potential to carbon reductions through more efficient fuel planning than the larger aircrafts (A330 and B757). Also, the $\mathrm{CO}_{2}$ production is more sensitive to TOW in smaller aircrafts than the larger ones in turbofan aircraft category.

As seen in the Table 3 , the $\mathrm{R}^{2}$ value of correlation between $\mathrm{CO}_{2}$ and number of passengers ranges from 0.007 to 0.070 for different aircrafts, which is not enough to establish any credible relation between the parameters' pair. The most notable reason for this uncertainty in the relationship is the fact that airline operators do not measure the exact weight of passengers on board their aircraft, but rather use a predefined average value accepted by regulatory bodies and the operator itself. While the actual passenger weights may vary to a large extent, this general rule uses one constant value for passenger weight which is in fact not very accurate in real-life scenario.

\subsection{Variations in $\mathrm{CO}_{2} / \mathrm{km}$}

The $\mathrm{CO}_{2} / \mathrm{km}$ with respect to the route distance $(\mathrm{km})$ has a decreasing trend, implying that with increase in 
Evaluation and mitigation analysis of carbon footprint for an airline operator: Case of Nepal Airlines Corporation

Table 3: $\mathrm{R}^{2}$ and gradient values for correlation with $\mathrm{CO}_{2}$

\begin{tabular}{lllllll}
\hline $\mathrm{CO}_{2}$ (Tons) & \multicolumn{3}{c}{ Correlation $\mathrm{R}^{2}$ value } & \multicolumn{2}{c}{ Regression Line Gradient } \\
\cline { 2 - 7 } vs. & $\mathrm{A} 330$ & $\mathrm{~B} 757$ & $\mathrm{~A} 320$ & $\mathrm{~A} 330$ & $\mathrm{~B} 757$ & $\mathrm{~A} 320$ \\
\hline Flight Time(Hrs) & 0.970 & 0.977 & 0.973 & 15.637 & 12.105 & 7.788 \\
Route Distance (km) & 0.897 & 0.923 & 0.941 & 0.018 & 0.014 & 0.009 \\
Fuel on Board (Tons) & 0.626 & 0.445 & 0.604 & 1.776 & 1.807 & 2.628 \\
Take-off Weight (kg) & 0.418 & 0.540 & 0.463 & 1.136 & 1.516 & 1.615 \\
Occupancy (\%) & 0.013 & 0.070 & 0.007 & 14.794 & 22.922 & -5.951 \\
\hline
\end{tabular}

Table 4: $\mathrm{R}^{2}$ and gradient values for correlation with $\mathrm{CO}_{2} / \mathrm{km}$

\begin{tabular}{lcccccc}
\hline $\mathrm{CO}_{2} / \mathrm{km}$ & \multicolumn{3}{c}{ Correlation $\mathrm{R}^{2}$ value } & \multicolumn{3}{c}{ Regression Line Gradient } \\
\cline { 2 - 7 } vs. & $\mathrm{A} 330$ & $\mathrm{~B} 757$ & $\mathrm{~A} 320$ & $\mathrm{~A} 330$ & $\mathrm{~B} 757$ & $\mathrm{~A} 320$ \\
\hline $\begin{array}{l}\text { Route } \\
\begin{array}{l}\text { Distance } \\
(\mathrm{km})\end{array}\end{array}$ & 0.359 & 0.440 & 0.553 & -0.0017 & -0.0016 & -0.0012 \\
\hline
\end{tabular}

route distance, the $\mathrm{CO}_{2}$ emission per kilometer flown decreases. This rate of decrease is more prominent in larger aircraft than the smaller ones as depicted by the gradient value of regression for the respective aircrafts as shown in Table 4. This statistical proof is in line with the theoretical basis that longer flight routes offer more of cruising time, (which utilizes lesser fuel than take-off and climb stages of flight), which thus reduces the per $\mathrm{km}$ emission for the whole flight.

\subsection{Variations in take-off weight}

Data for all three types of fleet show that the fuel on board is a major variable playing role in variations of TOW. That is also why FOB is a major contributing variable of $\mathrm{CO}_{2}$ emission as depicted in Table 5. Route type (represented by route distances) have average role to play in variations of TOW. Also, as seen in the data, number of passengers has as much more driving force in changes in TOW. Also, the gradient for A330 aircraft for TOW vs. pax has the largest value, which means that number of passengers is also an important factor for TOW even though as a whole, the pax doesn't have much driving force on $\mathrm{CO}_{2}$ emission.

\subsection{Effect of engine utilization on $\mathrm{CO}_{2}$}

Graphs of $\mathrm{CO}_{2}$ /engine utilization hour were plotted for individual aircraft to look into the effect of engine aging on the carbon emission. Representation of the data per aircraft along with the fleet type also helped find out maintenance status of the aircraft pertaining to its engines.

The Figure 3, 4 and 5 for $\mathrm{CO}_{2}$ emission with respect to engine utilization for all aircraft (except 9N-ALZ) show that the $\mathrm{CO}_{2}$ emission variation over time is in the range of \pm 0.35 tons of $\mathrm{CO}_{2}$ /engine hour utilization. This shows that there isn't significant change in car-

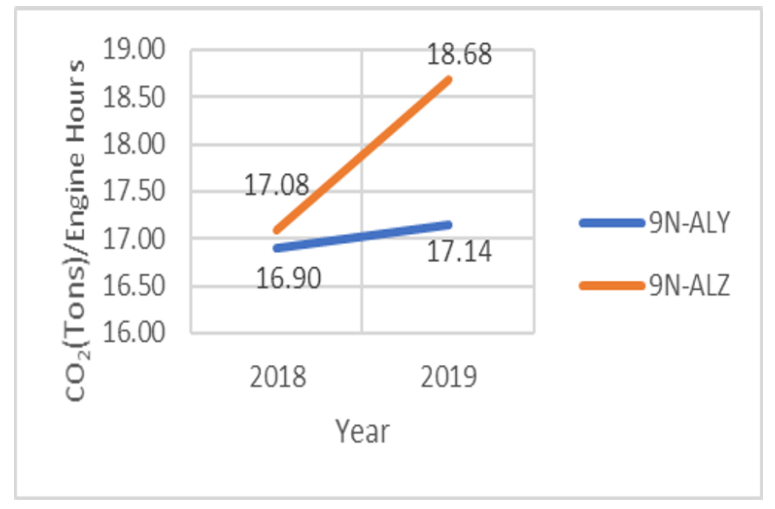

Figure 3: $\mathrm{CO}_{2}$ emission with respect to Engine Utilization for A330 aircrafts

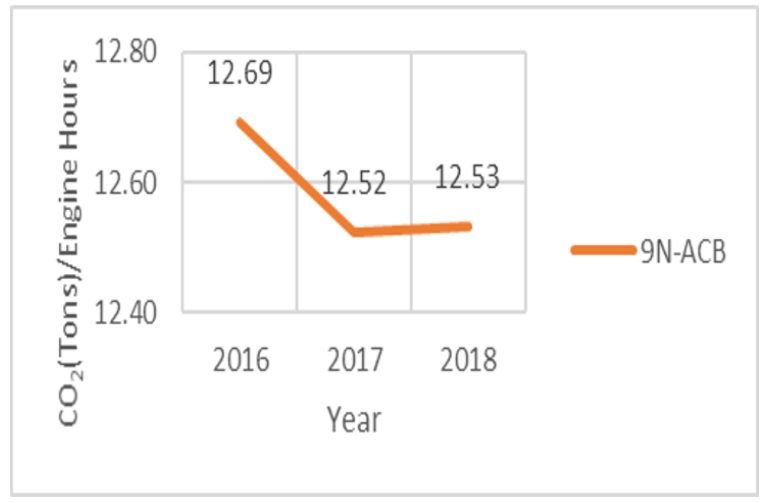

Figure 4: $\mathrm{CO}_{2}$ emission with respect to Engine Utilization for B757 aircraft (9N-ACB)

bon emissions with respect to the engine utilization, or aging. However, the data for A330 aircraft, 9N-ALZ, carbon emission increase by 1.6 tons/engine hour from 2018-2019. This could be some on going engine-related 
Evaluation and mitigation analysis of carbon footprint for an airline operator: Case of Nepal Airlines Corporation

Table 5: $\mathrm{R}^{2}$ and gradient values for correlation with TOW

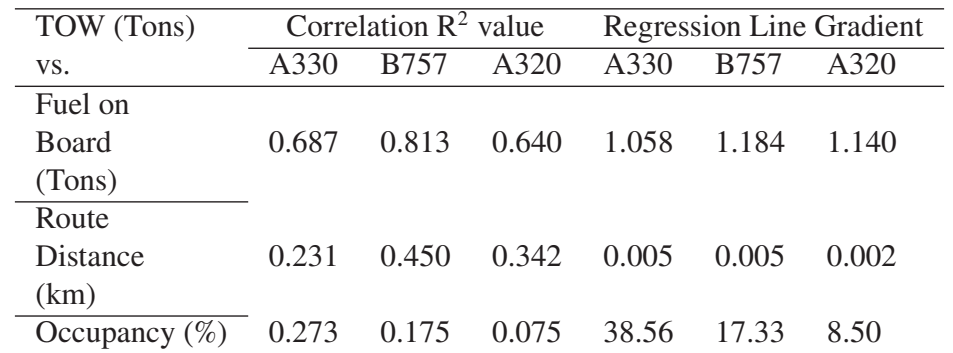

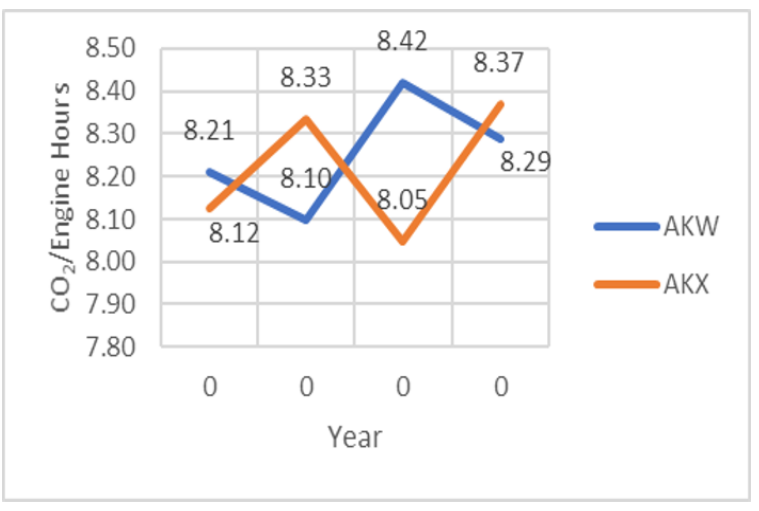

Figure 5: $\mathrm{CO}_{2}$ emission with respect to Engine Utilization for A320 aircrafts

problems, hard operation, or lapses in maintenance practices. Even though the $\mathrm{CO}_{2}$ /engine hour fluctuates over the years, there is a slight increasing trend for both A320 and $\mathrm{A} 330$ aircrafts. The subtle increase in $\mathrm{CO}_{2}$ emission is attributed to engine wear and tear as amidst compliance to maintenance requirements laid out by aviation authorities or OEMs.

Until such time comes when allowable engine parameters are met, the rate of carbon emission may increase. After that, the engine must go under inspection/overhaul under hard time use or overhaul as per its predefined life (called Life Limited Parts or LLPs), the objective of which is to restore back the performance of engines. Study of engine emission before and after such shop visit could put light on the effect of engine maintenance on performance of an engine.

\section{7. $\mathrm{CO}_{2}$ emission by APU}

An APU (Auxiliary Power Unit) is commonly provided in large aircrafts to provide power during in-flight engine failure, engine starting, electrical power and, airconditioning on ground. Sometimes the maintenance staff or cockpit crew also use APU as a means of lighting and electrical power during maintenance or flight preparation when Ground Power Units (GPU) are not available.
Graphs were prepared to find out the contribution of APU use in carbon emission and its variation over time that can give insight into operational use. For B757 aircraft, APU data has not been well documented and as such, this paper analyses the data for A330 and A320 aircrafts.

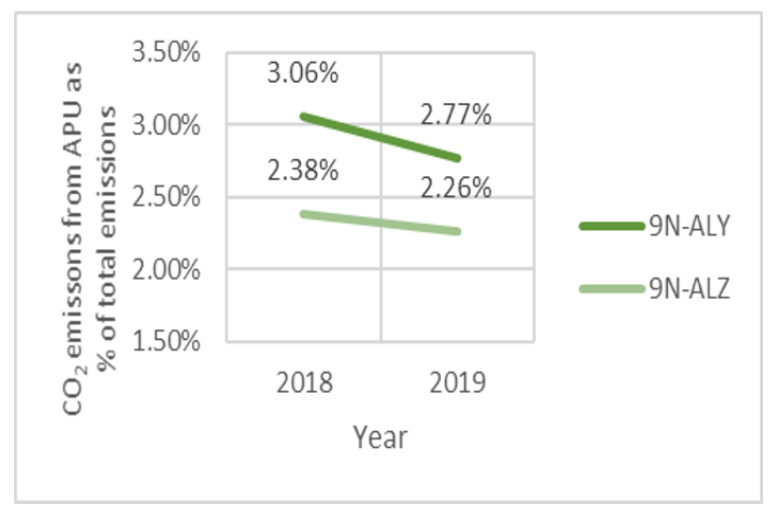

Figure 6: $\mathrm{CO}_{2}$ emission from APU as \% of total emissions for A330 aircraft

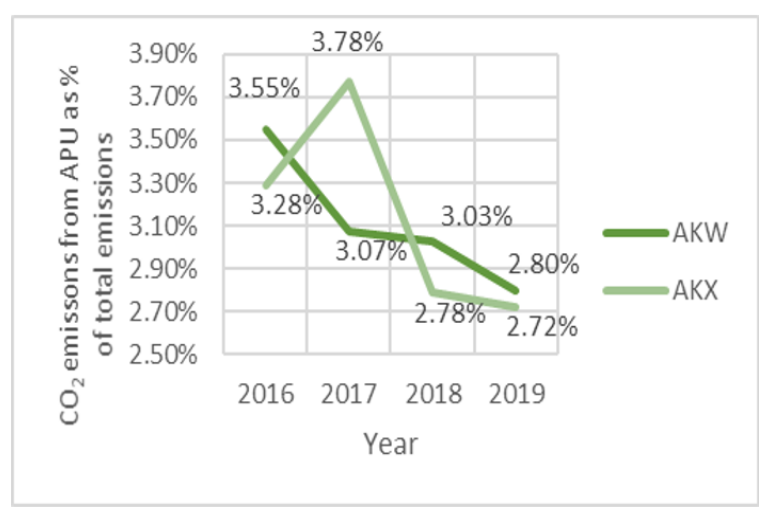

Figure 7: $\mathrm{CO}_{2}$ emission from APU as \% of total emissions for A320 aircraft

APU used in NAC's A330 aircraft is Honeywell GTCP331-350 whose fuel consumption per hour with maximum electrical and air conditioning load is taken as $210 \mathrm{~kg}$ as per Airbus [19]. The APU used in NAC's 
A320 aircraft is Pratt and Whitney APU APS 3200 with fuel consumption rate of $142 \mathrm{~kg} / \mathrm{hr}$ as per P\& W [20]. Industry standards puts APU fuel use as around 3\% of the total fuel burn. This fact is proven by the statistical data presented in Figure. 4 and 5. If we look at the yearly variation, we can see that there is a slight declining trend in APU emission with time. Even though the APU use hours are increasing over time, the ratio of APU emission per total emission is reducing.

\subsection{Comparison of aircrafts based on specific $\mathrm{CO}_{2}$ emission}

A standard parameter used to measure the carbon emission efficiency of different aircrafts is $\mathrm{CO}_{2} / \mathrm{pax}-\mathrm{km}$, which removes the passenger and distance factor, which are different for different fleet configuration and individual flights. Thus, this parameter can be used to compare $\mathrm{CO}_{2}$ emission among different aircrafts with aggregated data per year.

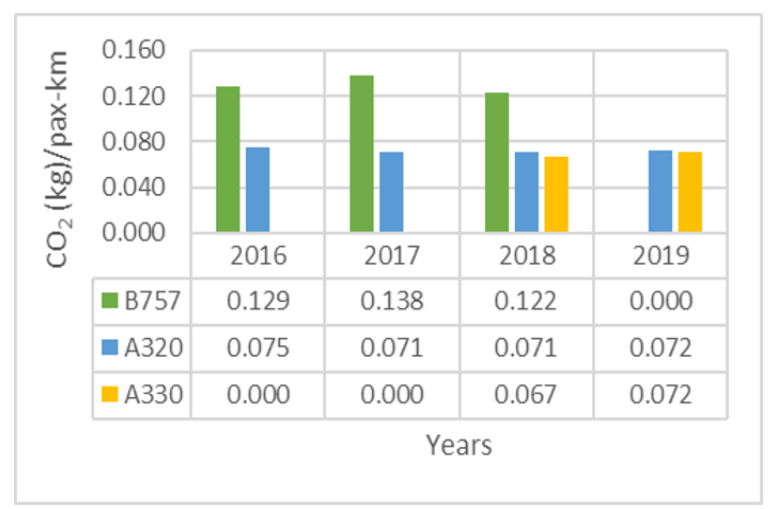

Figure 8: $\mathrm{CO}_{2} /$ pax-km for turbofan aircrafts

As seen in Figure. 8, the carbon emission per passenger and kilometer of flight travel depicts that newer aircraft contribute to lesser carbon emission. B757 aircraft is actually an older aircraft which is no longer in extensive commercial use in the world. This aircraft type is more than 35 years old and NAC's B757 aircrafts were in fleet for more than 30 years.

In contrast, NAC's A320 aircrafts are just over 4-5 years old while the A330 aircrafts are only over one years old as of 2019. A320 and A330 are one of the leading commercial aircrafts used for short and long-haul flight respectively. The statistical data thus shows that the older, B757 aircraft emits more specific carbon emissions than its newer counterparts i.e. A330 and A320. Also, A330 aircraft demonstrates better emission efficiency probably because it is newer than A320 aircraft.

Figure. 9 shows the same parameter for NAC's turboprop aircrafts which are operated in domestic sectors. As seen, Y12-E aircraft has the highest per passenger

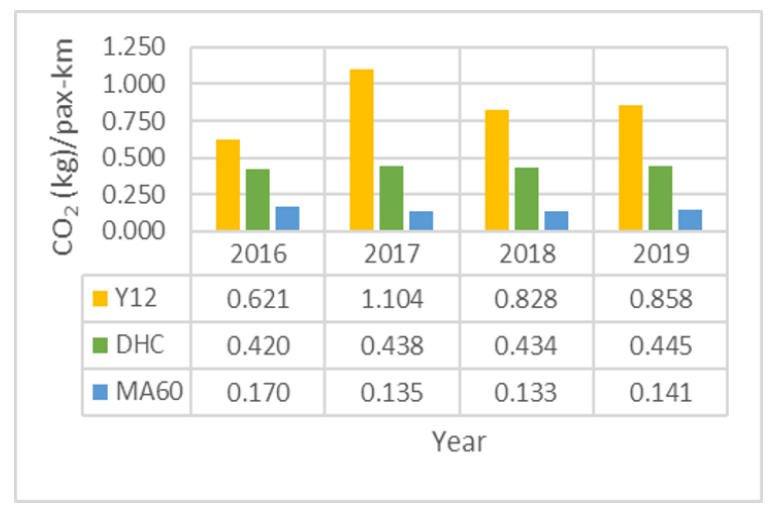

Figure 9: $\mathrm{CO}_{2} /$ pax-km or turboprop aircrafts

per km carbon emission capacity among the turboprop aircraft, followed by DHC-6/300 and MA60 aircraft. The chart is arranged in increasing number of seat capacity. The results obtained could be so because of the large sensitivity of passenger numbers per flight of respective aircrafts. Lower seat capacity means that even one passenger has capacity to differ the carbon emission per person by a large extent. The rule of newer aircraft being more efficient does not apply much to turboprop aircrafts as seen from the obtained results.

The information also shows that turboprop aircrafts in summation is less efficient in terms of carbon emission. This could be due to the inherent characteristics of turboprop aircrafts which have less seat capacity, less MTOW or their cruise altitude being lesser than their turbofan counterparts. Another major cause of this high carbon emission could be attributed to the fact that full passenger occupancy is not obtained probably due to poor commercial planning (NAC being national flag carrier of Nepal flies to many destinations in Nepal, a good portion of which, have poor passenger load, but NAC opts to operate in these sectors as a gist of service rather than commercial business). Also, there is underlying factor that NAC's turboprop aircrafts, DHC6/300 and Y12-E are operated in STOL (Short Take-off and Landing) sectors which often are in higher altitudes, downgrading the maximum passenger carrying capacity for some high-altitude flights. Also, in case for MA60, trunk routes are operated which are mostly in Nepal's Terai region where during summers, the hot, humid climate plays an evil role in decreasing the maximum allowable passenger capacity.

\section{9. $\mathrm{CO}_{2}$ emission of $\mathrm{NAC}$ ground handling operations}

Nepal Airlines Corporation carries ground handling operations for its domestic and international flights as well as for majority of foreign airlines operating at KTM. The 
ground handling operations includes services starting from marshalling to pushback. NAC uses equipment such as Ground Power Units (GPU), baggage tractors, passenger steps, conveyer belt loaders, ramp movement and passenger vehicles to provide the ground handling services. In 2019, the total $\mathrm{CO}_{2}$ emission from ground handling operations of NAC was 729.7 tons (considering emission factor of $2.66 \mathrm{~kg}$ of $\mathrm{CO}_{2}$ /liter of diesel burn and $2.29 \mathrm{~kg}$ of $\mathrm{CO}_{2}$ /liter of petrol burn). This corresponds to only $0.4 \%$ of the total $\mathrm{CO}_{2}$ emissions from collective airline and ground handling operations. The remaining $99.6 \%$ of the total emissions were from airline operations of NAC alone.

\subsection{0. $\mathrm{CO}_{2}$ forecasting for NAC}

Crystal Ball Predictor with iterations of 5000 was carried out to predict the $\mathrm{CO}_{2}$ emissions till 2030 with two scenarios: with impact of COVID-19 and without impact of COVID-19.

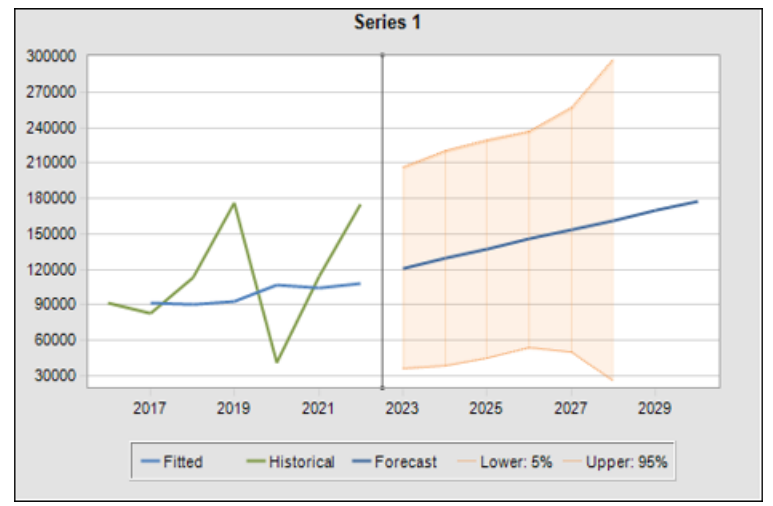

Figure 10: $\mathrm{CO}_{2}$ emission forecast for NAC till 2030 with impact of COVID-19

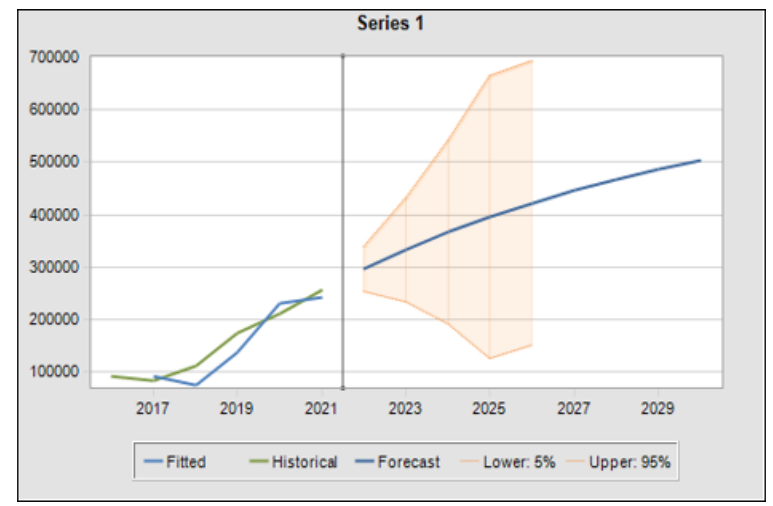

Figure 11: $\mathrm{CO}_{2}$ emission forecast for NAC till 2030 without impact of COVID-19

As seen in the figures, there is substantial effect of COVID-19 in the annual $\mathrm{CO}_{2}$ production rate along with the effect of decommissioning of Y12E and MA60 aircrafts. The best fitted forecast model was Damped Trend without seasonality which brought the $\mathrm{CO}_{2}$ emission to 178,025 tons in year 2030 . This value is almost equal to that of the value in 2019 . The possible variations in this value for the year, 2025 stands at 45,420229,555 (i.e. $26 \%-131 \%$ of total 2019 emission with $90 \%$ confidence interval.

The prediction model for $\mathrm{CO}_{2}$ emission without taking flight reductions due to COVID-19 showed that the $\mathrm{CO}_{2}$ value in 2030 would be 503,584 tons, which is nearly thrice the value of 2019 production. The possible variations in this value for the year, 2025 stands at 45,420-229,555 (i.e. 26\%-131\% of total 2019 emission) with $90 \%$ confidence interval.

This shows that the COVID-19 situation has caused a drop in flight operations which could affect the $\mathrm{CO}_{2}$ emissions till 2030, after which the net production may increase from 2019 values. Detailed data for the results obtained from CB predictor are presented in Appendix B.

\section{Discussion and mitigation}

From the regression and correlation analyses between different $\mathrm{CO}_{2}$ emission parameters and flight parameters, mitigation analysis has been able to be done. Possible mitigation and offsetting measures for turbofan aircrafts have been discussed here.

\subsection{Route Optimization}

The correlation and regression analysis between $\mathrm{CO}_{2} / \mathrm{km}$ and route distance show that longer distances offer lower carbon emission per km flown. On average, A330 and A320 can have deduction of 1.7 tons and 1.2 tons respectively of carbon emission per $1000 \mathrm{~km}$ flown. As such, short haul flight sectors like Kathmandu-Delhi, Bangalore, or Mumbai are not feasible sectors for A330 aircraft. Even for A320 aircraft, the Kathmandu-Delhi is not a good sector owing to the high carbon emission per $\mathrm{km}$ in this sector. However, the occupancy rates for Delhi flights are very good and is important from economic standpoint. In this backdrop, existing Kathmandu to Indian city pair flights are best fitted for A320 aircraft, and not A330 aircraft.

Mid-to-long range destinations like Bangkok, Kuala Lumpur, Hong Kong, Dubai and Doha are fairly good for both A320 and A330. However, since A330 is a wide body aircraft and has longer range, it is best suited for existing Osaka/Narita flights which are long-haul flights. NAC could reduce its carbon emission values by flying narrow body aircraft in short-haul and widebody aircraft in long-haul aircraft. Also, in future, if aircrafts are added to the existing fleet, newer (already 
proposed) destinations like Incheon and Riyadh should be allocated for A330 aircraft. For A320 aircraft, new proposed sector like Guangzhou could be more emission -friendly.

Apart from improving the carbon emission per km, NAC could reduce the carbon emission greatly if it applies ETOPS (Extended Twin Engine Operations) for its international sector aircrafts. ETOPS, as the name implies, is a rule that allows aircrafts to fly longer distances away from airports (like seas and deserts). The existing routes of NAC are non-ETOPS which means that flight routes are prepared in such a way to fly very near to existing airports.

Even though Airbus A330 and A320 aircrafts are ETOPS certified by the OEMs, they still need the operator (i.e., NAC)'s preparations in terms of fulfilling regulatory requirements (related to flight operations and maintenance) to be able to fly on ETOPS routes. If NAC is approved to carry ETOPS flight, destination airports can be flown to via more direct routes than on the paths defined by availability of airports, as shown in the figure below. As the route distance itself decreases, $\mathrm{CO}_{2}$ emission also decreases.

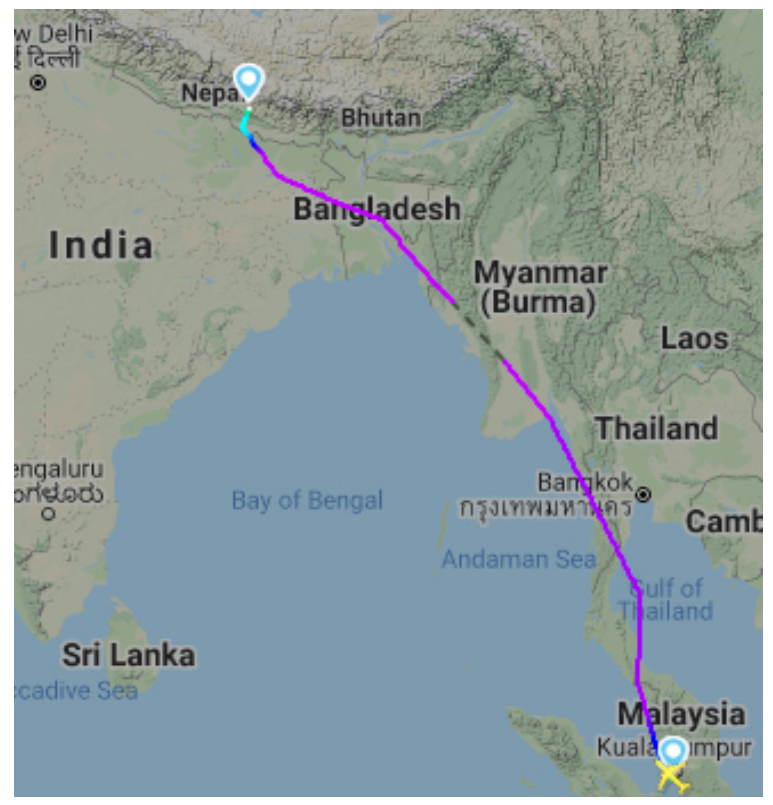

Figure 12: A Flight Radar flight path for Flight No: RA416 for a flight of 2020 via NAC's A320 aircraft for KUL-KTM flight

As an example, Figure. 12 shows the actual flight path from Kuala Lumpur to Kathmandu is such that the aircraft flies very less time over the oceans. This is because NAC cannot yet operate ETOPS flight. If NAC could operate this flight based on ETOPS rules, flights routes would allow aircrafts to fly directly to Kathmandu over the Bay of Bengal which could substantially reduce the route distance and thus $\mathrm{CO}_{2}$ emission also.

\subsection{Optimum Fuel Planning}

The fuel carried on board has a prominent effect on the take-off weight and in turn the $\mathrm{CO}_{2}$ emission. As discussed earlier, one-ton addition of FOB could increase the carbon emission by 1.78 tons for A320 and 2.63 tons for A330 aircraft. The study of fuel required per sector as per fuel policy of NAC and general airlines operators versus the actual FOB show that there is additional fuel carried on board than is required for the sector. Additional fuel than the required quantity is carried on board mostly on discretion of the Pilot in Command (PIC) with a mindset of preparation for on-route weather conditions or other safety reasons. However, we can demonstrate safe values for FOB in different sectors through the historical data of actual fuel burn. By this way, we can safely reduce the FOB and also reduce the carbon emissions to a good extent.

Monte Carlo simulation allows independent variables to change with a certain number of trials so that the total variations in dependent variables can be obtained. In cases where real data are not available, a pre-conceived distribution type and limits for the independent variables are set. However, in the case of this research, actual historical data are available, which is very helpful in automatically generating the limits and probability distributions for the independent variables. Table 6 summarizes the correlation parameter, $\mathrm{R}^{2}$ value between $\mathrm{CO}_{2}$ and parameters which are deemed causing factors of the carbon emission. Considering only $\mathrm{R}^{2}$ values which are greater than $50 \%$, we have flight time, route distance and FOB as the major contributing factors of $\mathrm{CO}_{2}$ emission. A multiple regression equation was formed using these variables, whose equation is as follows:

$$
\begin{aligned}
\mathrm{CO}_{2}= & -0.00039 \times \text { Route Distance }+ \\
& 7.241 \times \text { Flight Times }+ \\
& 0.5288 \times \text { FOB }-3.448
\end{aligned}
$$

Flight time and FOB have been identified as the controllable variables here while changes in route distance need more planning with wider scope of efforts. As there is a trend of increase in flight time over the years, the flight time has been considered to be kept to the level of 2016 values. The required FOB has been calculated from fuel policies of NAC whose main contents are:

Taxi Fuel : Fuel required for engine start, taxi and APU use : $200 \mathrm{~kg}$ for A320 aircraft

Trip Fuel : Fuel required for normal flight from take-off and landing : taken average from historical data 
Evaluation and mitigation analysis of carbon footprint for an airline operator: Case of Nepal Airlines Corporation

Table 6: Monte Carlo Simulation Results for $\mathrm{CO}_{2}$ reductions

\begin{tabular}{|c|c|c|c|c|}
\hline Sector & From & To & $\begin{array}{l}\text { Certainty } \\
\text { of } \mathrm{CO}_{2} \\
\text { reductions }\end{array}$ & $\begin{array}{l}\text { Maximum possible } \\
\text { reduction with } \\
50 \% \text { certainty }\end{array}$ \\
\hline Short- & KTM & DEL & $75.47 \%$ & 1.69 Tons \\
\hline haul & DEL & KTM & $93.74 \%$ & 2.19 Tons \\
\hline Long- & KTM & $\mathrm{DOH}$ & $85.78 \%$ & 3.35 Tons \\
\hline haul & $\mathrm{DOH}$ & KTM & $93.87 \%$ & 3.33 Tons \\
\hline
\end{tabular}

Reserve Fuel : Includes contingency fuel, alternate fuel, final reserve fuel and additional fuel : Fuel for 5-10\% of trip fuel, goaround to cruising altitude and landing and holding of 45 minutes at holding speed at $1500 \mathrm{ft}$.

Extra Fuel : Extra fuel on discretion of PIC (Pilot in Command)

Using this theory, the required FOB for different sectors have been calculated. A320 is a mid-range aircraft and in case for NAC, KTM-DEL-KTM (Distance = 926/928 km) is considered a short-haul flight and KTMDOH-KTM $($ Distance $=3669 / 3724 \mathrm{~km})$ is considered a long-haul flight for A320 aircraft. As such, Monte Carlo simulation was carried out to find the possible $\mathrm{CO}_{2}$ reductions in these flights. Probability distribution and limits for independent variables were generated from historical data of 2016-2019 while the formula for forecast value for $\mathrm{CO}_{2}$ is: (Route distance and constant terms cancel out.

$$
\begin{aligned}
\Delta \mathrm{CO}_{2}= & 7.241 \times \Delta \text { Flight Time }+ \\
& 0.5288 \times \Delta \text { FOB }
\end{aligned}
$$

Where,

$$
\begin{aligned}
\Delta \text { Flight Time }= & \text { Actual Flight Time }- \text { Optimum } \\
& \text { Flight Time } \\
\Delta \text { FOB } & =\text { Actual FOB }- \text { Optimum FOB }
\end{aligned}
$$

The actual values will be changed by the simulation while the optimum values have been obtained from the methodology explained above. Carrying 5,000 iterations, the results obtained are as in Table 6

As seen in the table above, out-bound flights from Nepal have lesser certainty of $\mathrm{CO}_{2}$ reductions than the inbound flights. This could be due to economic value of fuel in Nepal being more expensive than foreign countries, which might have opted pilots to carry more fuel during in-bound flights.

Another finding is that short-haul flights have lesser opportunity for $\mathrm{CO}_{2}$ emission than long-haul flights. In average, with reductions in flight time (through better management strategies) and FOB, reductions of up to 2.19 tons in short-haul sector and 3.55 tons in long-haul sector could be achieved with $50 \%$ certainty. The simulation results have been attached in Appendix C.

\subsection{Carbon taxing}

Carbon tax is a concept wherein, taxes are included in air fare that gains revenues for the airline operator which can be used to buy carbon credits from credible sources in order to offset the carbon emission that it makes. Moreover, the airline operator can also invest independently in non-carbon emitting projects like clean energy infrastructures to offset the carbon it produces during flight operations.

A correlation and regression analysis of $\mathrm{CO}_{2} /$ pax versus the route distance of Table. 7 shows that there is fair correlation between the route distance and $\mathrm{CO}_{2} / \mathrm{pax}$. The gradient value of regression line shows that the $\mathrm{CO}_{2}$ /pax value is almost constant with number of passengers. This implies that a constant rate of tax could be added to air fare of all air routes irrespective of the route distance.

Even though the main agenda of carbon taxing is to gain extra revenue for the airline operator to invest in carbon friendly projects, effects of carbon tax could be negative, like decrease in air travel or shift towards automotive transportation which could increase automotive carbon emission while decreasing aviation emission on one hand. But it is pointed that there will be net $\mathrm{CO}_{2}$ reductions in aggregate as per Hofer et. al. [21].

\subsection{Slot management}

Slot management refers to planning of flight departure and arrival times. Many-a-while, flight delays occur, or flight times are extended because there is much traffic on ground for take-off, taxiing and landing [22]. In case of Kathmandu airport, the problem lies in airport bays for aircraft turn around which leads to holding while arriving at the airport. In case of foreign airports, large volume of on ground aircraft movement and in some cases, weather conditions cause the flight time to be stretched especially during taxiing phase. As the flight time directly affects the $\mathrm{CO}_{2}$ emissions, proper slot 
Evaluation and mitigation analysis of carbon footprint for an airline operator: Case of Nepal Airlines Corporation

Table 7: $\mathrm{R}^{2}$ and gradient values for correlation with $\mathrm{CO}_{2} / \mathrm{pax}$

\begin{tabular}{lcccccc}
\hline $\mathrm{CO}_{2} /$ pax & \multicolumn{3}{c}{ Correlation $\mathrm{R}^{2}$ value } & \multicolumn{3}{c}{ Regression Line Gradient } \\
\cline { 2 - 7 } vs. & $\mathrm{A} 330$ & $\mathrm{~B} 757$ & $\mathrm{~A} 320$ & $\mathrm{~A} 330$ & $\mathrm{~B} 757$ & $\mathrm{~A} 320$ \\
\hline $\begin{array}{l}\text { Route } \\
\begin{array}{l}\text { Distance } \\
(\mathrm{km})\end{array}\end{array}$ & 0.404 & 0.326 & 0.719 & 0.00006 & 0.00006 & 0.00005 \\
\hline
\end{tabular}

management of departure and arrival at different airport according to their least traffic timings could provide carbon emission reductions. This is easy to say, but to implement, there is need for cooperation between airlines and the airport authorities/service providers to cater to reduction in flight hours as each airline wants least air time for itself and planning with cooperation can create a win-win situation for all airlines. Wherever possible, slot planning should be done keeping in mind to reduce the flight's air time.

\subsection{Shift towards newer aircrafts}

As is discussed in Figure 9, newer aircrafts produce lesser per capita $\mathrm{CO}_{2}$ emissions than the older counterparts. Thus, if NAC were to expand its fleet, it should opt for buying aircrafts of newer technologies. It should be borne in mind that when selecting newer aircrafts, the mainstream aircrafts should be of choice because of its proven performance and easy access to OEM's operational and maintenance support for airline operators.

\section{Conclusions}

Results of data analysis using Excel tools show that $\mathrm{CO}_{2}$ emission from a multi-fleet airline like NAC has most of its carbon emission coming from larger aircrafts and should concentrate to emission mitigation based on its large aircraft fleet. In case for domestic-sector operating smaller aircrafts (turboprop aircrafts), reduction in carbon emission could be obtained from increasing its passenger occupancy rate through better commercial strategies while for internationally-operating larger aircrafts, there are various possible methods by which an airline operator like NAC could make net reductions in its $\mathrm{CO}_{2}$ inventory.

The results from correlation and regression analysis for international fleet show that $\mathrm{CO}_{2}$ emissions are primarily affected by the flight time and route distance. Also, the fuel on board an aircraft for specific flight is also a parameter of interest since there is statistical relation between $\mathrm{CO}_{2}$ emission and $\mathrm{FOB}$, mostly due to the fact that more FOB increases TOW, which has effects on $\mathrm{CO}_{2}$ emissions too. In most of the cases of international flight more FOB is seen to be taken aboard on a flight than what is required for that particular flight as per the calculations of fuel policy, Reductions in FOB could be suggested for operating flights of NAC to demonstrate practical reductions in net $\mathrm{CO}_{2}$ emission of NAC.

Air time of various city pairs are fluctuating over time most of which are increasing. Even a small amount of increase in flight time such as 5 minutes can increase $\mathrm{CO}_{2}$ to a great extent incase of large aircrafts. The problem seems to lie in destination and departure airports being congested. This could be mitigated by doing planning of airport slots for minimal flight and turn-around time.

Number of passengers, though having substantial effects on carbon emission do not affect the emissions from larger aircrafts and thus, passenger number is out of equation for mitigation analysis in international-sector fleet. Engine utilization have some effect on the net $\mathrm{CO}_{2}$ emissions (i.e., increasing effect) mostly because of gradual wear and tear

\section{Funding source}

This research did not receive any specific grant from funding agencies in the public, commercial, or not-forprofit sectors.

\section{Acknowledgements}

We would like to thank Mr. Prabhash Kumar Karmacharya, Mr. Amit K.C., Mr. Chakra Nakarmi, Ms. Prakriti Koju, Sr. Capt. Deepu Raj Jwarchan, Er. Amrit Thapa and Er. Rupesh Shrestha (NAC) for their assistance in providing maintenance and operations data. We would also like to thank Mrs. Sarju Tuladhar for her assistance in proofreading this paper.

\section{References}

[1] CarbonTrust. Carbon Footprinting Guide[J/OL]. 2020. https: //www.carbontrust.com/resources/carbon-footprinting-guide.

[2] CarbonTrust. Briefing: What are Scope 3 emissions?[R/OL] $2020 . \quad$ https://www.carbontrust.com/resources/carbonfootprinting-guide.

[3] Fahey D W, Baughcum S L, Fuglestvedt J S, et al. White Paper on Climate Change: Aviation Impacts on Climate State of Science[J/OL]. ICAO Environmental Report, 2016: 99-107. https://www.icao.int/environmental-protection/Documents/ 
ScientificUnderstanding/EnvReport2016-WhitePaperClimateChange.pdf.

[4] Scheelhaase J D. How to regulate aviation's full climate impact as intended by the EU council from 2020 onwards[J/OL]. Journal of Air Transport Management, 2019, 75: 68-74. DOI: https://doi.org/10.1016/j.jairtraman.2018.11.007.

[5] Intergovernmental panel on Climate Change. Aviation and the Global Atmosphere[R]// Intergovernmental panel on Climate Change. 1999.

[6] ICAO Environment. Market-Based Measures[R/OL]. 2020. http://www.icao.int/environmental-protection/Pages/.

[7] Penner J E, Lister D H, Griggs D J, et al. IPCC Special Report Aviation and the Global Atmosphere[J/OL]. 1999: 373. http: //books.google.com/books?id=JgphajrWfOsC $\{Z \mathbf{Z}\}$ printsec $=$ frontcover $\{\%\}$ Cnpapers2://publication/uuid/9E05EEA8894A-47FE-9C27-96F5A5B9D387.

[8] EASA. European Aviation Environmental Report 2019: 1[R/OL]// Ege Üniv. Ziraat Fak. Derg. 2019: 8794. https://www.eurocontrol.int/publication/european-aviationenvironmental-report-2019.

[9] CAAN. CAAN Carbon Offsetting and Reduction Scheme for International Aviation (CORSIA) Requirements[R]// Civil Aviation Authority of Nepal, Kathmandu Nepal. 2020.

[10] Schaltegger S, Csutora M. Carbon accounting for sustainability and management. Status quo and challenges[J/OL]. Journal of Cleaner Production, 2012, 36: 1-16. DOI: https://doi.org/ 10.1016/j.jclepro.2012.06.024.

[11] Vaughan A. Offsetting on your holidays[J/OL]. New Scientist, 2019, 243(3239): 20-21. DOI: https://doi.org/10.1016/s02624079(19/31324-7.

[12] Baumeister S. 'Each flight is different': Carbon emissions of selected flights in three geographical markets[J/OL]. Transportation Research Part D: Transport and Environment, 2017, 57: 1-9. DOI: https://doi.org/10.1016/j.trd.2017.08.020.

[13] U.C. Rai, P. Shrestha, R. KC, P. KC, I. Paudel, D.K. Limbu, S. Paudel, R. Meyer, V. Singh, M. Hall, A. Fernqvist, S. Karanjit, K. Sigdel R R, Paudyal A. Carbon Neutrality Report 2018[R/OL]// Yeti Airlines Pvt. Ltd. 2019. https://yetiairlines.com/file- manager/files/2/ Final(CarbonNeutralityReport2018/.pdf.

[14] Yang H, O'Connell J F. Short-term carbon emissions forecast for aviation industry in Shanghai[J/OL]. Journal of Cleaner Production, 2020, 275. DOI: https://doi.org/10.1016/ j.jclepro.2020.122734.

[15] Debbage K G, Debbage N. Aviation carbon emissions, route choice and tourist destinations: Are non-stop routes a remedy?[J/OL]. Annals of Tourism Research, 2019, 79. DOI: https://doi.org/10.1016/j.annals.2019.102765.

[16] ICAO. ICAO Carbon Emissions Calculator Methodology, Version 8, 2017[R]. 2017: 3-11.

[17] Melis D J, Silva J M, Silvestre M A, et al. The effects of changing passenger weight on aircraft flight performance $[\mathrm{J} / \mathrm{OL}]$. Journal of Transport and Health, 2019, 13: 41-62. DOI: https://doi.org/ 10.1016/j.jth.2019.03.003.

[18] Scotti D, Volta N. An empirical assessment of the co2sensitive productivity of European airlines from 2000 to 2010[J/OL]. Transportation Research Part D: Transport and Environment, 2015, 37: 137-149. DOI: https://doi.org/10.1016/ j.trd.2015.04.009.

[19] Airbus. Getting to grips with fuel economy[J/OL]. 2004 (4): 24-26. https://ansperformance.eu/library/airbus-fueleconomy.pdf.

[20] Pratt and Whitney AeroPower. APU Engine Center[M/OL]// PWAeropower. 2020. http://pwaeropower.com/en/apu-enginecenter/our-products.

[21] Hofer C, Dresner M E, Windle R J. The environmental effects of airline carbon emissions taxation in the US[J/OL]. Transportation Research Part D: Transport and Environment, 2010,
15(1): 37-45. DOI: https://doi.org/10.1016/j.trd.2009.07.001.

[22] Postorino M N, Mantecchini L, Paganelli F. Improving taxiout operations at city airports to reduce $\mathrm{CO} 2 \mathrm{emissions}[\mathrm{J} / \mathrm{OL}]$. Transport Policy, 2019, 80: 167-176. DOI: https://doi.org/ 10.1016/j.tranpol.2018.09.002. 


\section{Appendix A.}

Appendix A.1. Route distance between city pairs for international sectors

\begin{tabular}{|c|c|c|c|c|c|c|c|}
\hline \multicolumn{2}{|c|}{ IATA Code for Airports } & \multirow[t]{2}{*}{ From } & \multirow[t]{2}{*}{ To } & \multirow{2}{*}{$\begin{array}{l}\text { Route Distance } \\
\qquad(\mathrm{km})\end{array}$} & \multirow[t]{2}{*}{ From } & \multirow[t]{2}{*}{ To } & \multirow{2}{*}{$\begin{array}{l}\text { Route Distance } \\
\qquad(\mathrm{km})\end{array}$} \\
\hline KTM & Kathmandu & & & & & & \\
\hline DEL & Delhi & KTM & DEL & 926 & DEL & KTM & 926 \\
\hline BLR & Bangalore & KTM & BLR & 2145 & BLR & KTM & 1993 \\
\hline BOM & Mumbai & KTM & BOM & 1902 & BOM & KTM & 1778 \\
\hline KUL & Kuala Lumpur & KTM & KUL & 3595 & KUL & KTM & 3537 \\
\hline BKK & Bangkok & KTM & BKK & 2363 & BKK & KTM & 2391 \\
\hline HKG & Hongkong & KTM & HKG & 3493 & HKG & KTM & 3519 \\
\hline $\mathrm{DOH}$ & Doha & KTM & $\mathrm{DOH}$ & 3669 & $\mathrm{DOH}$ & KTM & 3724 \\
\hline DXB & Doha & KTM & DXB & 3341 & DXB & KTM & 3150 \\
\hline KIX & Osaka & KTM & KIX & 5495 & KIX & KTM & 5484 \\
\hline
\end{tabular}

Appendix A.2. Route distance between city pairs for domestic sectors

\begin{tabular}{llllclcc}
\hline \multicolumn{2}{l}{ IATA Code for Airports } & From & To & $\begin{array}{c}\text { Route Distance } \\
(\mathrm{km})\end{array}$ & From & To & $\begin{array}{c}\text { Route Distance } \\
(\mathrm{km})\end{array}$ \\
\hline KTM & Kathmandu & KTM & PPL & 133 & PPL & KTM & 133 \\
PPL & Bangalore & KTM & TPJ & 254 & TPJ & KTM & 254 \\
TPJ & Taplejung & KTM & BGL & 181 & BGL & KTM & 181 \\
BGL & Baglung & KTM & BHP & 172 & BHP & KTM & 172 \\
BHP & Bhojpur & KTM & LUA & 144 & LUA & KTM & 144 \\
LUA & Hongkong & KTM & HRJ & 80 & HRJ & KTM & 80 \\
HRJ & Chaurjhari & KTM & RUK & 96 & RUK & KTM & 96 \\
RUK & Rumjatar & KTM & TMD & 119 & TMD & KTM & 119 \\
TAL & Talcha & KTM & TAL & 152 & TAL & KTM & 152 \\
IMK & Simikot & KTM & HRJ & 80 & HRJ & KTM & 80 \\
FEB & Sanfebagar & KTM & IMK & 215 & IMK & KTM & 215 \\
DOL & Dolpa & KTM & FEB & 133 & FEB & KTM & 133 \\
BJR & Bajura & KTM & DOL & 156 & DOL & KTM & 156 \\
BIR & Biratnagar & KTM & BJR & 157 & BJR & KTM & 157 \\
DHI & Dhangadi & KTM & BHP & 78 & BHP & KTM & 78 \\
KEP & Nepalgunj & KTM & BIR & 232 & BIR & KTM & 232 \\
BDP & Bhadrapur & KTM & DHI & 489 & DHI & KTM & 489 \\
PKR & Pokhara & KTM & KEP & 370 & KEP & KTM & 370 \\
SIF & Simara & KTM & BDP & 294 & BDP & KTM & 294 \\
BWA & Bhairahawa & KTM & PKR & 146 & PKR & KTM & 146 \\
DNG & Dang & KTM & SIF & 67 & SIF & KTM & 67 \\
LUA & Lukla & KTM & BWA & 194 & BWA & KTM & 194 \\
& & KTM & DNG & 124 & DNG & KTM & 124 \\
& & KTM & LUA & 191 & LUA & KTM & 191 \\
\hline & & & & & & \\
\hline
\end{tabular}




\section{Appendix B.}

Appendix B.1. CB Predictor Results for $\mathrm{CO}_{2}$ forecast with COVID-19 effects

\begin{tabular}{llll}
\hline Year & Lower: 5\% & Forecast & Upper: 95\% \\
\hline 2023 & 35992 & 121272 & 206552 \\
2024 & 38629 & 129380 & 220131 \\
2025 & 45420 & 137487 & 229555 \\
2026 & 54233 & 145595 & 236957 \\
2027 & 49812 & 153702 & 257593 \\
2028 & 25786 & 161810 & 297835 \\
2029 & - & 169918 & - \\
2030 & - & 178025 & - \\
\hline
\end{tabular}

Appendix B.2. CB Predictor Results for $\mathrm{CO}_{2}$ forecast witouth COVID-19 effects

\begin{tabular}{llll}
\hline Year & Lower: 5\% & Forecast & Upper: 95\% \\
\hline 2022 & 254926 & 297811 & 340695 \\
2023 & 234912 & 334459 & 434005 \\
2024 & 191917 & 367283 & 542648 \\
2025 & 127950 & 396681 & 665413 \\
2026 & 151473 & 423013 & 694553 \\
2027 & - & 446597 & - \\
2028 & - & 467720 & - \\
2029 & - & 486639 & - \\
2030 & - & 503584 & - \\
\hline
\end{tabular}




\section{Appendix C.}

Appendix C.1. Simulation Results for $\mathrm{CO}_{2}$ reductions in KTM-DEL and DEL-KTM sector

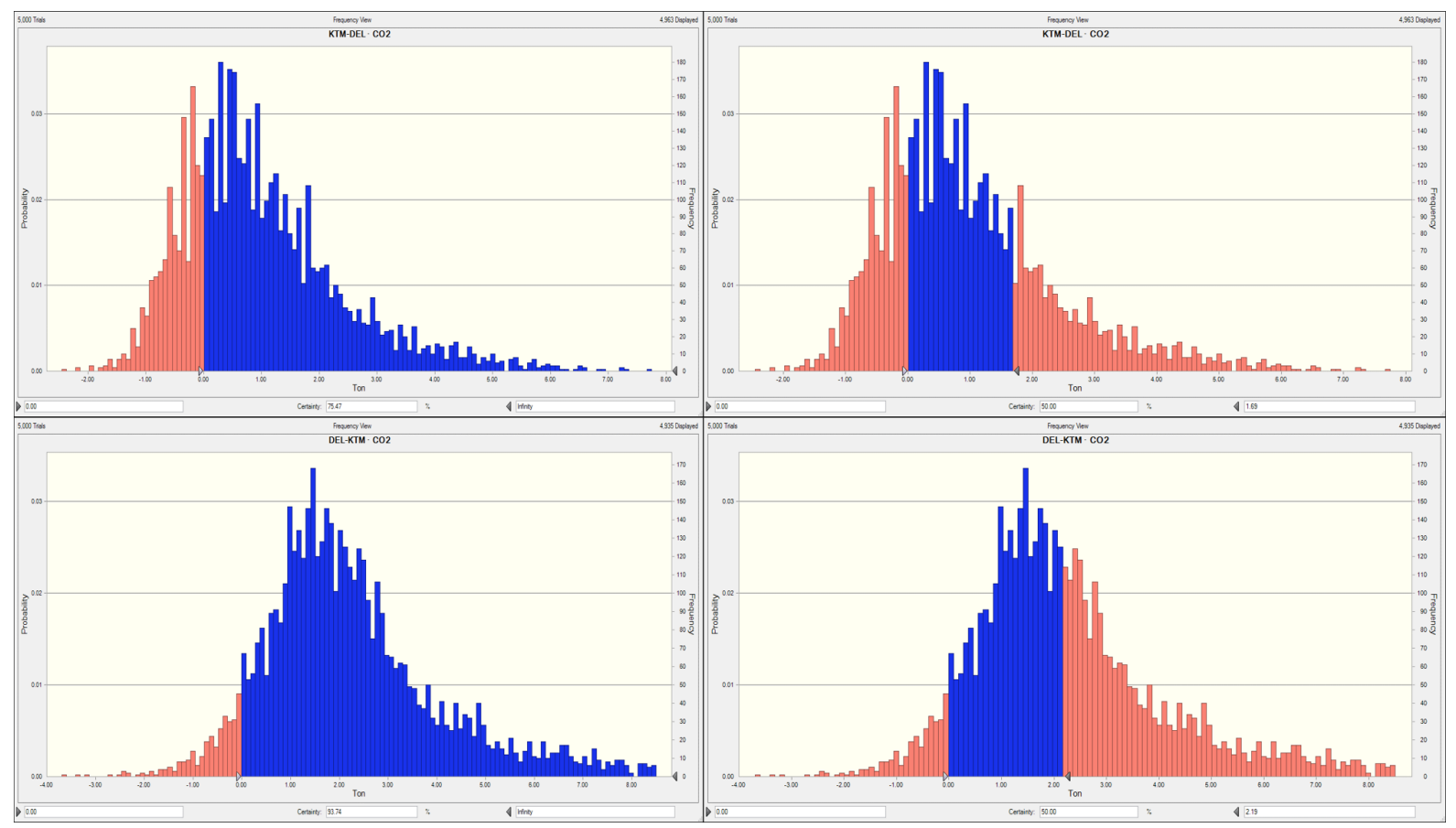

Appendix C.2. Simulation Results for $\mathrm{CO}_{2}$ reductions in KTM-DOH and DOH-KTM sector

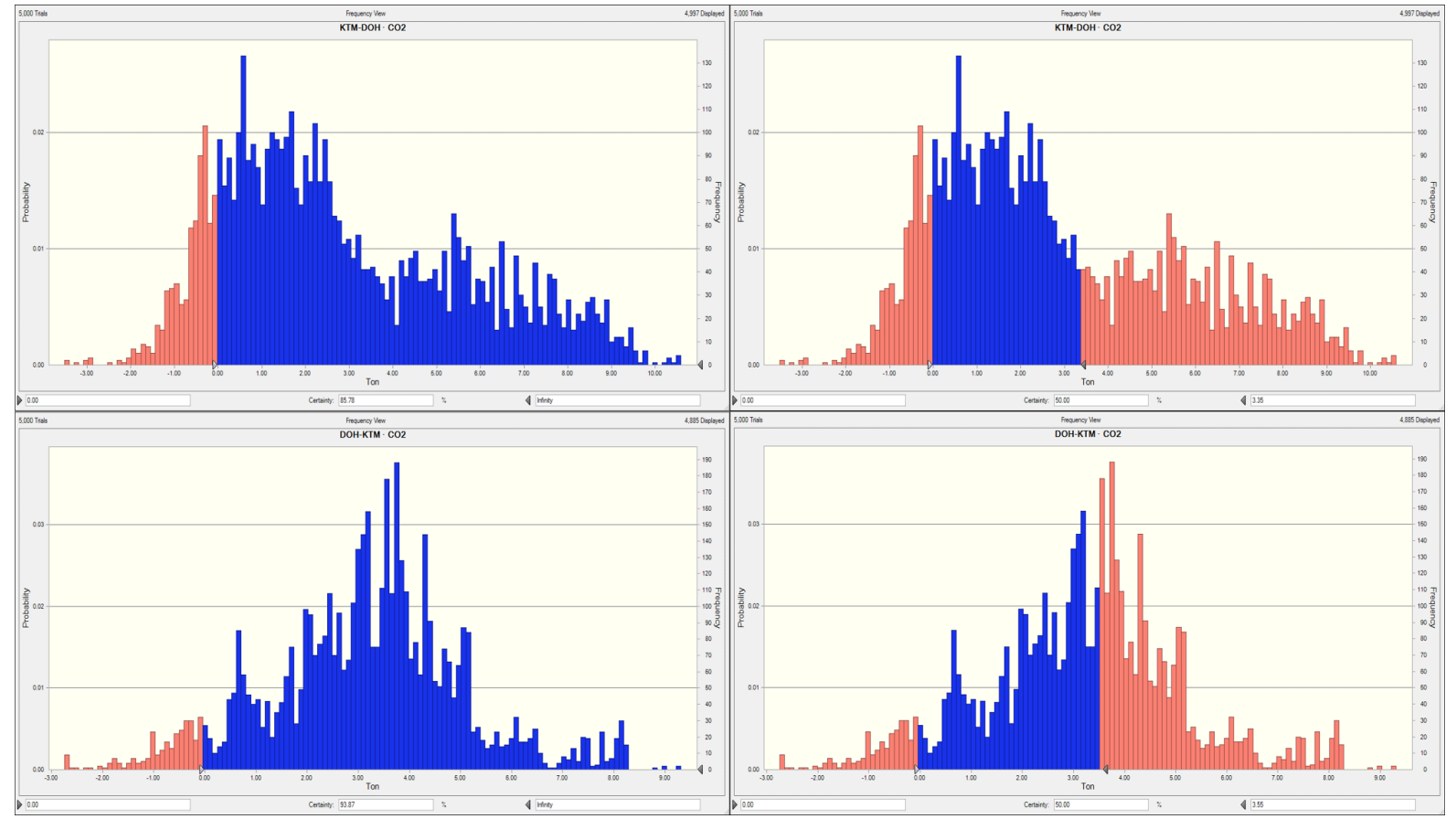

